\title{
PARAMETRIC MODELLING (BIM) FOR THE DOCUMENTATION OF VERNACULAR CONSTRUCTION METHODS: A BIM MODEL FOR THE COMMISSARIAT BUILDING, OTTAWA, CANADA.
}

\author{
S. Fai ${ }^{\text {a }}$, M. Filippi ${ }^{\text {a }}$, S. Paliaga ${ }^{\text {a }}$ \\ ${ }^{\text {a }}$ Carleton Immersive Media Studio (CIMS), Azrieli School of Architecture and Urbanism, Carleton University, 1125 \\ Colonel By Drive, Ottawa, Canada K1S5B6 \\ sfai@cims.carleton.ca \\ maurofilippi@cims.carleton.ca \\ silviapaliaga@cims.carleton.ca
}

KEY WORDS: architectural heritage, parametric modelling, building information modelling, Canadian architecture.

\begin{abstract}
:
Whether a house of worship or a simple farmhouse, the fabrication of a building reveals both the unspoken cultural aspirations of the builder and the inevitable exigencies of the construction process. In other-words, why buildings are made is intimately and inevitably associated with how buildings are made. Nowhere is this more evident than in vernacular architecture. At the Carleton Immersive Media Studio (CIMS) we are concerned that the de-population of Canada's rural areas, paucity of specialized tradespersons, and increasing complexity of building codes threaten the sustainability of this invaluable cultural resource. For current and future generations, the quantitative and qualitative values of traditional methods of construction are essential for an inclusive cultural memory. More practically, and equally pressing, an operational knowledge of these technologies is essential for the conservation of our built heritage. To address these concerns, CIMS has launched a number of research initiatives over the past five years that explore novel protocols for the documentation and dissemination of knowledge related to traditional methods of construction. Our current project, Cultural Diversity and Material Imagination in Canadian Architecture (CDMICA), made possible through funding from Canada's Social Sciences and Humanities Research Council (SSHRC), explores the potential of building information modelling (BIM) within the context of a web-based environment.
\end{abstract}

In this paper, we discuss our work-to-date on the development of a web-based library of BIM details that is referenced to 'typical' assemblies culled from 19C and early 20C construction manuals. The parametric potential of these 'typical' details is further refined by evidence from the documentation of 'specific' details studied during comprehensive surveys of extant heritage buildings. Here, we consider a BIM of the roof truss assembly of one of the oldest buildings in Canada's national capital — the Commissariat Building and current home to the Bytown Museum — as a case study within the CDMICA project.

\section{INTRODUCTION}

"For though in practical knowledge every complete example may bear the credit of a rule; yet peradventure rules should precede that we may be made fit to judge examples."

(Henry Wotton 1624)

\subsection{Context: the CDMICA Project}

Cultural Diversity and Material Imagination in Canadian Architecture (CDMICA) is a Partnership Development Project, funded by the Social Sciences and Humanities Research Council of Canada (SSHRC). The objective of CDMICA is to establish a digital platform for a network of professionals and scholars concerned with the conservation and management of knowledge related to vernacular and ethno-cultural methods of construction in Canada. CDMICA brings together academics, heritage professionals, and industry leaders in software development to investigate the possible benefits that web-based technology and building information modelling (BIM) may offer for knowledge management in the documentation, conservation, and maintenance of architectural heritage. While not discussed specifically in this paper, our research includes the evaluation of Industry Foundation Classes (IFC) as a possible international standard for heritage documentation and the integration of point-cloud data - acquired through laser scanning and photogrammetry — into a BIM environment.

CDMICA was launched in September 2011, with current funding through September 2013. If our work generates sufficient interest from the heritage community, we are hoping to further develop the project with international partners.

The dataset for CDMICA is assembled from diverse sources including: construction manuals, specifications, and catalogues used in Canada between 1825 and 1925; buildings and landscapes documented specifically for the project by the CDMICA team; buildings and landscapes documented by CIMS for other projects. In addition, our Federal Government partners (Heritage Conservation Directorate, Public works and Government Services Canada; Canadian Register of Historic Places, Parks Canada) have agreed to provide CDMICA with access to their collections and to contribute expertise in both the documentation of heritage buildings and in the management of archival material. The assets and expertise offered by these federal agencies is augmented by our partnership with the Canadian Centre for Architecture (CCA) and the Archives and Research Collections (ARC) at Carleton University. Our 
industry partner, Autodesk Research, bring the technical guidance and software resources that are essential to realize our research objectives. In addition, our partnerships with the Heritage Canada Foundation and ICOMOS Canada offer a critical voice as well as providing a window to the international heritage community.

CDMICA has two distinct but affiliated lines of inquiry. In the first, we are assembling a library of construction manuals and trade journals used in Canada between 1825 and 1925 - a period of significant and diverse ethnic immigration - to develop a BIM inventory of typical building details. In order to determine what qualifies as typical, we are surveying the texts and assembling timelines that register technological shifts in building assemblies over the course of the temporal period under study. Further, the resulting BIM is referenced to the various texts that are used to construct the model - not unlike footnotes. Some construction technologies, such as wood, change dramatically in this period. Others, like stone, show less change. The second line of inquiry involves modelling specific details using information gathered from on-site surveys of in situ buildings. The buildings are identified using the Canadian Register of Historic Places (http://www.historicplaces.ca/) and are chosen because they are representative of a specific community and specific historical moment. By comparing the typical to the specific, we are able to identify variations in methods of construction and further study if these variations are the result of exigency, technology, whimsy, or culture. We believe that the history of these variations is a rich field for ongoing research. Further, if variations appear repeatedly at the same point over a number of specific examples, we work to explore the range of variation and to establish parameters that take advantage of the parametric modelling capabilities of BIM software. These parametric models facilitate on-going research in using BIM to evaluate building performance, rehabilitation criteria, and life cycle management for heritage buildings.

\subsection{BIM and Heritage Buildings}

While there is still resistance in some sectors, it appears that BIM will become the Architecture, Engineering, Construction (AEC) industry standard for the design, construction, and management of new buildings. (Butler 2011; Eastman et al 2008; Russell et al 2008). If this is the case, it is imperative that professionals involved in the conservation and rehabilitation of architectural heritage be conversant with this technology. While not widespread, the use of BIM in the fields of heritage documentation and conservation is not without precedent. Arayici (2008), for example, advocates the adoption of BIM for existing buildings in order to move beyond rote 3D visualization through the incorporation of multifunctional, intelligent and multi-representational data. Penttila et al. (2007) offer a case study that evaluates the possibility of BIM for the retrofit of buildings of significant historical and cultural value. Their paper employs the concept of an "inventory model" as an essential base for a well-structured inventory of data that captures both the past and present condition of an existing building condition. Murphy et al (2011; see also Dore et al 2012) have proposed a novel application of BIM - HBIM (Historic Building Information Modelling) - that is developed for the GraphisSoft ArchiCAD platform using GDL scripting. HBIM offers a library of parametric building objects (column capitals, column shafts, etc.) that follow the proportional rules of the classical orders, in particular those laid out in 19C pattern books. These objects can be mapped on to meshes developed from pointcloud data. While HBIM is a valuable tool for the modelling elements of classical and neo-classical buildings, it appears less well suited to some types of building assemblies typical in Canada (e.g. wood frame). This is a question for further research.

CIMS has been involved in research for BIM applications in heritage documentation and rehabilitation since 2008 (see: http://www.210king.com; Attar et al. 2010; Fai et al 2011; Fai 2010). BIM is also the focus for a number of non-heritage projects in our research program. (www.cims.carleton.ca)

\subsection{The Commissariat Building / Bytown Museum}

For this paper, in the context of CDMICA, we will focus our discussion on a single building in Canada's National Capital and consider the value of BIM for modelling fine architectural details - both specific and typical — in heritage structures. Level of detail (LoD) relative to investment has been discussed by Leite et al (2011) where it is concluded that "....more detail in a model does not necessarily mean more modelling work; and such additional effort can lead to higher precision better supporting decisions during design and construction." (Leite $e t$ al 608) In addition, the authors state "...the chosen LoD for a given task should be determined by the purpose of it's usage." (Leite et al 608) In our study, we are interested in testing the range of scales that are possible in a single BIM and to establish protocols, including the investment needed for each LoD, that can serve as a guide for future academic research and for professional applications. While this paper looks specifically at the micro, the Commissariat Building is part of a larger BIM (now under construction) that incorporates the surrounding landscape, including Canada's Parliamentary Precinct and the eight lock stations that connect the Rideau Canal to the Ottawa River and

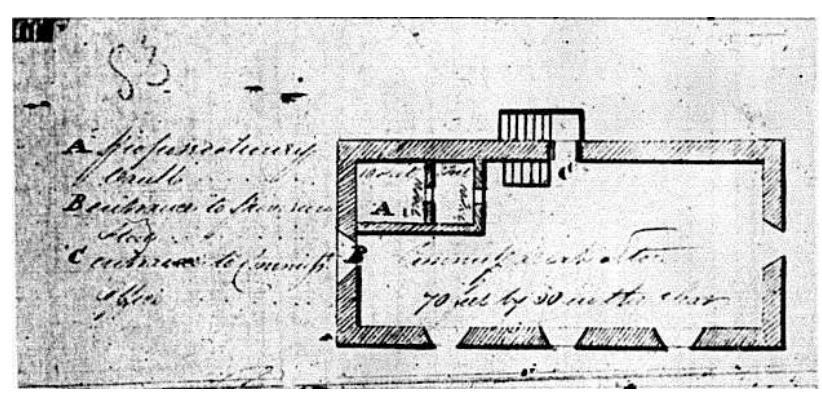

Figure 1. Sketch plan of Commissariat building, first floor, showing location of proposed treasury vault and dated: 15 February 1830. (Library and Archives Canada, R.G., 2, Vol.50, p.83)

The Commissariat Building was stabilized and restored in 1984. It has significant historic value for the region - being the oldest stone building in the city and the only remaining building associated with the construction of the Rideau Canal. Built in 1827 , by the Royal Sappers, under the command of Colonel John By, the building is a testament to the highly skilled Scottish masons who formed part of the corps.

(http://www.passageshistoriques-heritagepassages.ca)

As part of the Rideau Canal Unesco World Heritage Site (inscription in 2007), the Commissariat Building is well maintained by Parks Canada and has been the home to the Bytown Museum for more than fifty years. The landscape surrounding the museum is almost unchanged from the early 19C, contributing to the unique character of the building. The site attracts thousands of visitors every year. 


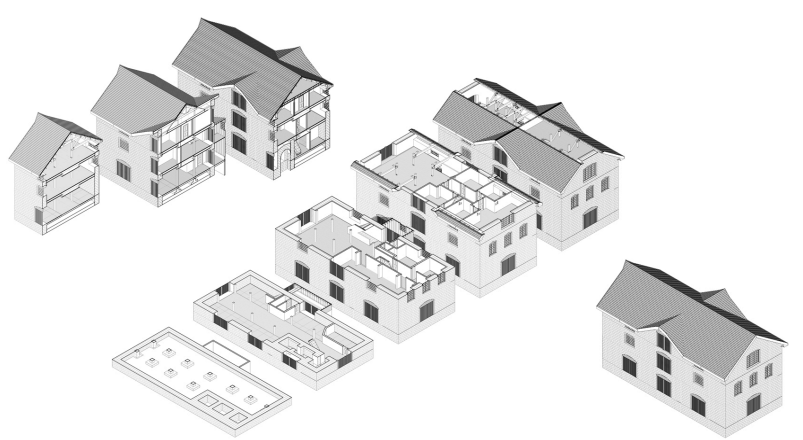

Figure 2. Commissariat Building, BIM plan / cross-sections

\section{FROM THE SURVEY TO THE MODEL}

In addition to a metric survey of the structure - using handmeasures, a Leica disto, and Leica Total Station - archival research uncovered drawings from 1826 (Fig.1), photographs from the late 19 and early $20 \mathrm{C}$, and a comprehensive set of drawings prepared for Parks Canada in 1984, as part of the stabilization project mentioned above (Fig. 3). Based on this information, a BIM was developed using Autodesk Revit 2012, with parametric categories or 'families' representing each part of the building (Figure 4). As part of the larger CDMICA project, a series of geo-referenced terrestrial laser scans, captured by a Leica Scanstation 2, were used to map the site and to accurately locate the model in the landscape. In this case, however, the pointcloud was not used in the construction of the Commissariat Building BIM. Two very focused graduate students built the model, without automation, over a period of seven weeks. While their knowledge of Revit at the beginning of the project was at an intermediate level, they did have access to the library of 'typical' BIM details under development by CIMS, existing CIMS protocols for BIM modelling, and other graduate students with an advanced knowledge of Revit.

From the foundation to the roof ridge, each element of the model belongs to its own family and can be adjusted individually and parametrically. The specific, and in some instances idiosyncratic, details of the Commissariat Building were used to inform the parametric potential of the 'typical' details built from construction and builder's manuals of the period. By assigning the appropriate geometric and material parameters to each component, the BIM offered the possibility of using the families (or their property settings) to model variations between similar details. In other words, using the library of 'typical' parametric details made it relatively easy to reconfigure any component to model a 'specific' detail encountered during the documentation process. As an example, we will discuss the timber structure of the roof to illustrate how to work between typical and specific details for the modelling of heritage buildings. (Fig. 5)

The roof of the Commissariat Building is structured by a series of unique king post trusses. It has a double pitch along the North-South axis, with a central dormer on either side along the East-West axis (Fig. 6). Due to the intersecting dormers, the central truss differs from the other trusses in its assembly. However, because it is composed of elements similar in geometry to the typical truss, it was possible to create it by modifying parameters of the parent family.

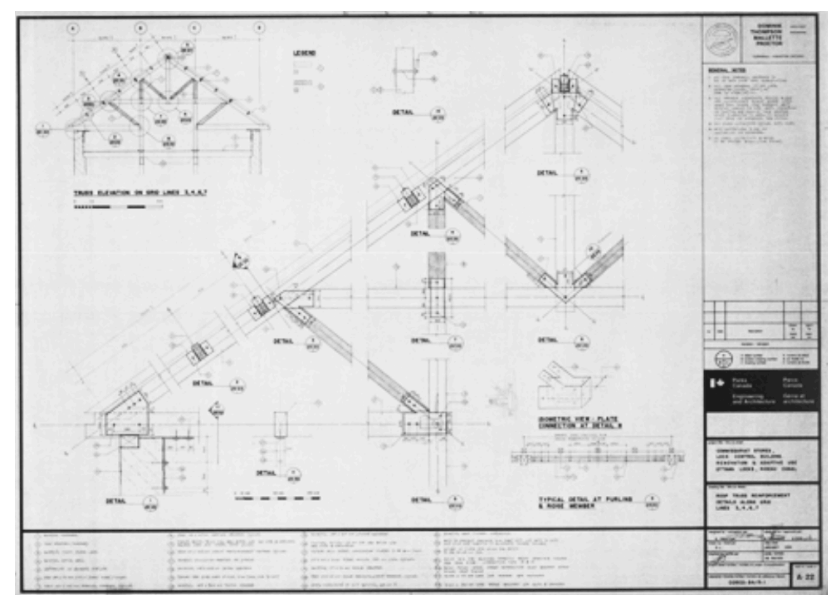

Figure 3. Sheet 22 "Roof Truss Reinforcement, Commissariat Stores, Lock Control Building. Renovation and Adaptive Use, Ottawa Locks, Rideau Canal." (Dominik, Thompson, Mallette, Proctor Architect / Engineers for Parks Canada 1984)

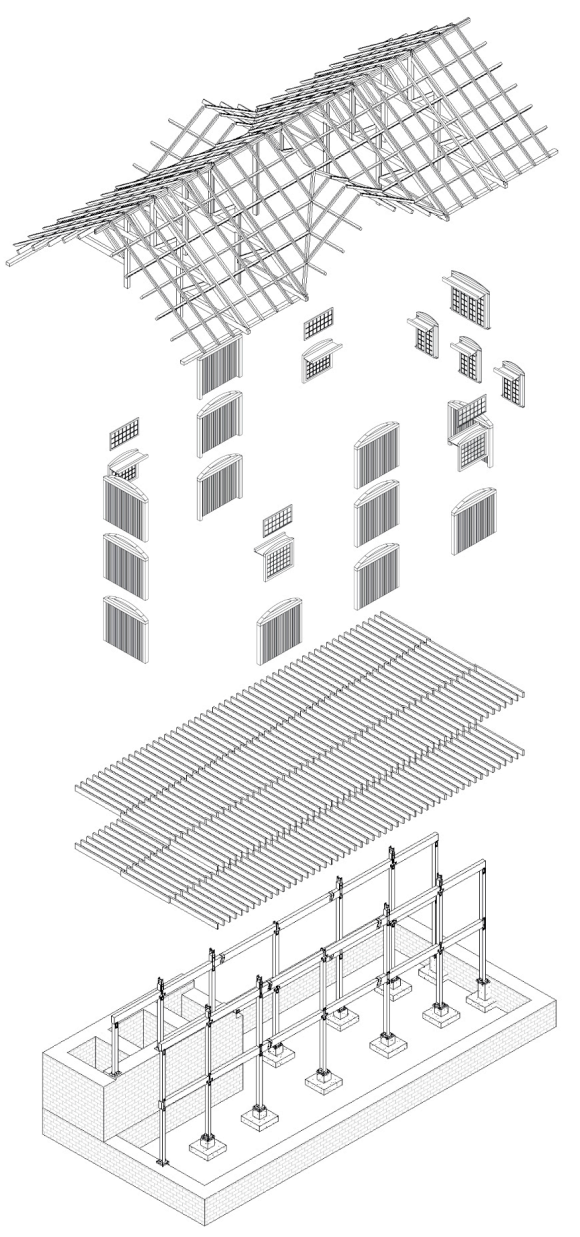

Figure 4. Parametric categories: 1. Footings and vertical structure; 2. Horizontal structure; 3. Openings; 4. Roof structure. Roof and wooden trusses 


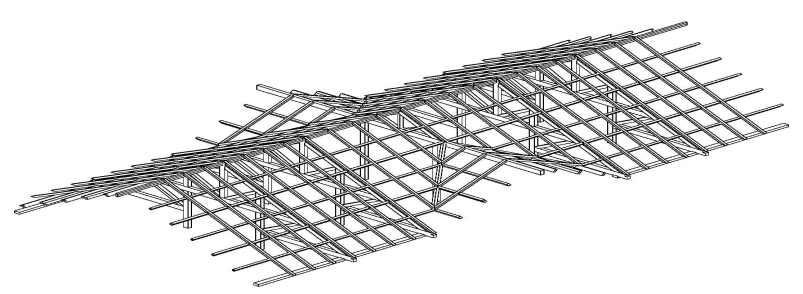

Figure 5. Roof structure

\subsection{Elements and joints}

In our review of builder's and construction manuals, we were unable to find an identical match for the king post configuration of the Commissariat Building. While the span is more consistent with that of a queen post truss, the builders chose to modify a king post truss into a kind of hybrid between the two. A BIM of a typical truss from the CDMICA library with similar qualities - Macey's "Queen Post Roof (Macy 1898) provided the basis for the Commissariat truss.

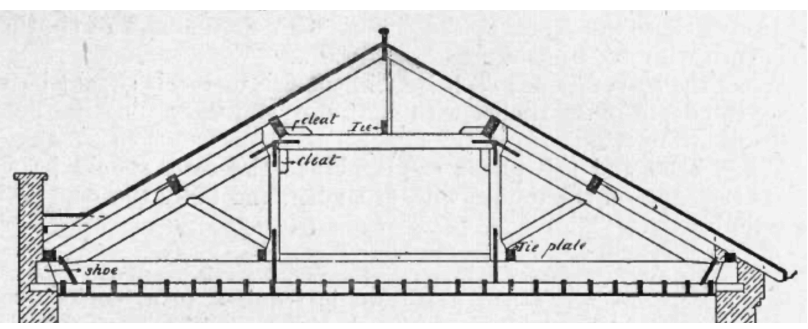

Figure 6. Frank Macy “Queen Post Roof”

The Commissariat truss is composed of a king post that is anchored by mortise and tenon to a tie beam below and closed laterally by two sloping rafters (Figure 6). The tie beam connects to the rafter at approximately two thirds of the rafter's length. Two additional tie beams connect the base of the rafters to columns. Finally, there are two struts within the lower portion of the truss that stiffen the structure and another two within the top portion that are partially supported by two posts that bear on the columns. The quasi-queen post configuration of the lower half of the truss provides additional headroom for the attic space - similar to Macy's Queen Post Roof.

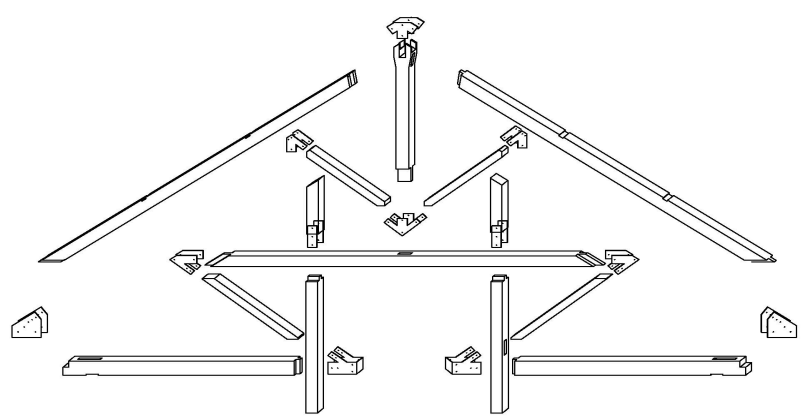

Figure 7. Commissariat truss structure

\subsection{Geometries and parameters}

Each of the elements described above have a specific and distinct geometric feature, including different profiles for the joints. For example, the transverse terminal faces of each element have different slopes and setbacks. Using parametric angles and lengths in plan and elevation allowing for each individual and unique, truss to be modelled from a single matrix of origin. In this way, the whole truss can take on different configurations, proportions, and patterns, and it can be reused and re-appropriated where necessary. The parameters common to more than one component allow each element to be modified according to the other elements they are connected to. Once the parameters are assigned to the lengths and general size of the joints connecting the various elements, it is possible to generate infinite specific configurations starting from generic elements even if these elements differ from the matrix of origin (Figure 7,8 ).

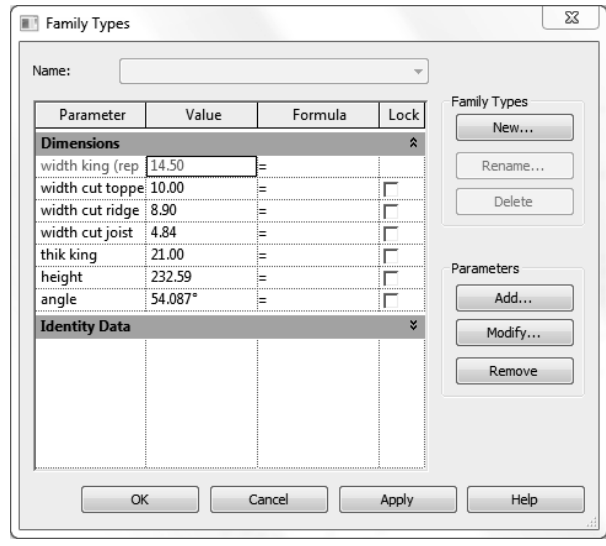

Figure 8. King Post parameters
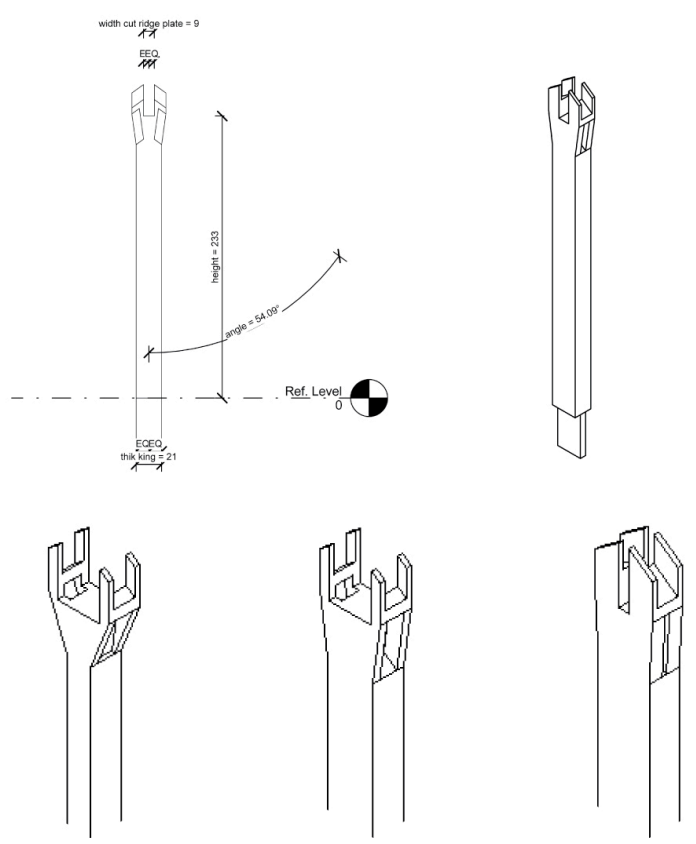

Figure 9. King Post component model, examples of possible geometric variations 


\section{CONCLUSIONS}

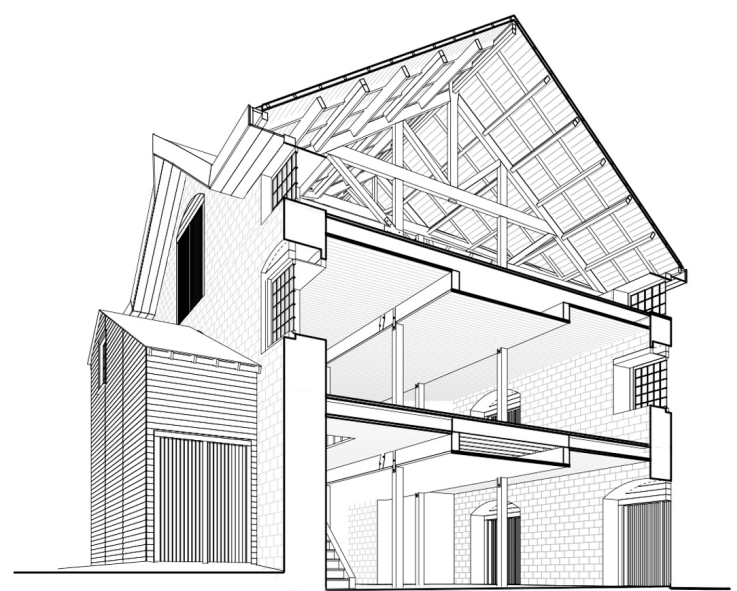

Figure 10. Commissariat Building, BIM perspectival section

Our study considers the challenges, limits, and advantages of using a BIM for the documentation of architectural heritage. While BIM is optimized for industrial building systems, we have demonstrated that it is possible to take advantage of the parametric components that are inherent in the software in order to create highly detailed and unique iterations of typical construction details.

As one of the oldest buildings in Canada's National Capital and as part of the Rideau Canal World Heritage Site, the Commissariat Building is recognized internationally as a cultural asset. However, while the craftsmanship demonstrated in the construction of the building is recognized as a character defining element, (see: http://www.historicplaces.ca/en/repreg/place-lieu.aspx?id=11116\&pid=1087\&h=Rideau,Canal),

CDMICA is the first attempt to document the materials and methods of construction in a format that will make these qualities evident and readily available for study. The 'specific' BIM details related to the Commissariat Building can serve as the basis for future conservation and rehabilitation of the structure, but they also contribute to our understanding of both why and how the building was assembled as it is. Knowing the exact number of bolts in the joints of a truss, where the wood came from, who built it, and where the builder came from can be easily integrated and quickly extrapolated from a wellplanned BIM. We argue that the centralization of these various sources of information can benefit the restoration, conservation, and management of this important heritage building as well as contribute to an integrated record of the more intangible aspects of the construction process.

The CDMICA library of parametric BIM details will freely available via the web in September 2013. This will include all reference material used in the development of the BIM library.

\subsection{References and Selected Bibliography}

References from Journals:

Arayici, Y. 2008. Towards building information modelling for existing structures, Structural Survey, 26(3), pp. $210-222$.

Butler, R. M. 2011. Message from the U.S. National CAD Standard Project Committee, Journal of Building Information Modelling, Spring, p. 11.
De Luca, L., Busayarata, C., Stefania, C., Véronb, P., Florenzanoa, M., 2011. A semantic-based platform for the digital analysis of architectural heritage, Computer and Graphics, 35(2), pp. 227-241.

Garagnani, S. 2012. Building Information Modeling semantico e rilievi ad altarisoluzione di siti appartenenti al Patrimonio Culturale (Semantic Building Information Modeling and high definition surveys for Cultural Heritage sites), DISEGNARECON, Numero Speciale, pp. 297-300.

Leite, F., Akcamete, A., Akinci, B., Atasoy, G., Kiziltas, S., 2011. Analysis of modeling effort and impact of different levels of impact of detail in building information models, Automation in Construction, 20, 601-609.

Murphy, M., McGovern, E., and Pavia, S., 2011. Historic Building Information Modelling — adding intelligence to laser and image based surveys," Int. Arch. Photogramm. Remote Sens. Spatial Inf. Sci., XXXVIII-5/W16, pp. 1-7.

\section{References from Books:}

Eastman, C., Teicholz, P., Sacks, R., Liston, K., 2008. BIM Handbook: A Guide to Building Information Modelling. John Wiley \& Sons, Hobken, NJ.

Fai, S., 2010. Material Imagination and Religious Architecture in Saskatchewan, Heritage 2010. Editors R. Amoêda, S. Lira \& C. Pinheiro. Greenlines Institute: Barcelos, Portugal.

Macey, F. W. 1898. Specifications in Detail. E. and F.N. Spon, London.

Wotton, H. 1624/1903. The Elements of Architecture, collected by Henry Wotton $\mathrm{K}^{\mathrm{t}}$ from the best Authors and Examples. Longmans, Green and Company, London, p. x.

\section{References from Other Literature:}

Attar, R., Prahbu, V. Glueck, M., Khan, A., 2010. 210 King Street: A Dataset for Integrated Performance Assessment, $\operatorname{Sim} A U D$, Orlando,

Armstrong-Reynolds, M. E., 2009. Eleven Buildings, Northern Area, Rideau Canal, Ontario, Federal Heritage Buildings Review Office, Report 91-131 to 91-175.

Dore, C., Murphy, M., 2012. Integration of Historic Building Information Modeling and 3D GIS for Recording and Managing Cultural Heritage Sites, 18th International Conference on Virtual Systems and Multimedia, Milan, Italy, pp. 369-376.

Fai, S., Graham, K., Duckworth, T., Wood, N., Attar, R., 2011. Building Information Modelling and Heritage Documentation, XXIII CIPA International Symposium, Prague, Czech Republic.

Fai, S., Duckworth, T., Graham, K., Wood, N., 2011. Building Information Modelling and the Conservation of Modern Heritage, The 24the World Congress of Architecture, Union International des Architects (UIA). Tokyo, Japan.

Mihindu, S., Arayici, Y., 2008. Digital Construction through BIM Systems will drive the Re-engineering of Construction Business Practices, International Conference on Visualization IEEE Computer Society, pp. 29-34.

Pauwels, P., Verstaeten, R., De Meyer, R., Van Campenhout, J., 2008. Architectural Information Modelling for Virtual Heritage Application, Digital Heritage - Proceedings of the 14th 
International Conference on Virtual Systems and Multimedia, pp. 18-23.

Penttilä, H., Rajala, M., Freese, S. 2007. Building Information Modelling of Modern Historic Buildings, Predicting the Future, 25th eCAADe Conference Proceedings, pp. 607-613.

Penttilä, H. 2005. The State of the Art of Finnish Building Product Modelling Methodology, Learning from the Past a Foundation for the Future, Special publication of papers presented at the CAAD futures, Vienna, pp. 225-240.

Russell, P; Elger, D. 2008. The Meaning of BIM: Architecture in Computro, Proceedings of the 26th eCAADe Conference, Antwerpen, pp. 531-536. 